\title{
IS POSITIVE-CONTRAST MYELOGRAPHY OF VALUE IN ACUTE CERVICAL SPINAL CORD INJURY?
}

\author{
By A. T. Scher, M.B., Ch.B., D.M.R.D. \\ Spinal Injuries Unit, Conradie Hospital, Cape Town, South Africa
}

\begin{abstract}
Positive-contrast myelography in 30 patients with acute cervical spinal cord injury has not provided any information of clinical value. Reference to the literature does not provide a definite set of indications for myelography in acute spinal cord injury. An attempt has therefore been made to evaluate the indications for this procedure. The potential hazards of myelography in patients with acute spinal cord injury are discussed. Specific contra-indications are described. Difficulties in the radiological interpretation of the usual myelographic appearances in spinal cord injury are mentioned. The advantages of negative-contrast myelography are briefly described. It is concluded that there is a very limited indication for positive-contrast myelography in acute spinal cord injury.
\end{abstract}

Key word: Myelography.

\section{Introduction}

MYELOGRAPHY in a patient with acute cervical spinal cord injury is a difficult procedure for the radiologist and a potentially hazardous examination for the patient. During the 4 years $1972-75$, 333 patients with partial or complete tetraplegia due to cervical spinal cord trauma were admitted to the Spinal Cord Injury Unit. Sixty-four patients had sustained stab wounds into the spinal cord, while motor vehicle accidents, industrial accidents, assaults and sport injuries were the cause of paralysis in the remainder.

Myelograms were preformed on 30 of these patients. In those patients who underwent myelography, no findings of any practical value in the management of the patient were obtained. In view of the difficulty and risk of the procedure, and lack of benefit to the patient, an attempt has been made to clarify the indications for, and contra-indications to, myelography in acute cervical spinal cord injury.

For practical purposes the only positive contrast medium which can be used for cervical myelography is myodil (iophendylate). The recently introduced water-soluble contrast media are unsafe for use in the cervical spinal canal.

\section{Potential Hazards of Myelography}

\section{Risk of Increasing the Degree of Paralysis}

Inadvertent movement of the patient's neck may well further traumatise an already damaged spinal cord. Rogers (1957) in his series of spinal cord injuries records a Io per cent deterioration in neurological deficit while the patient was undergoing treatment and diagnosis in the acute phase of paralysis. Myelography entails moving the patient (usually on skull traction with Crutchfield tongs) from the ward to the X-ray department. The patient must then be placed on the X-ray table, turned into the lateral position for the lumbar puncture and then placed either supine or prone. The supine position is more comfortable for the patient, but the myodil will often not flow in a satisfactory manner into the upper cervical sub-arachnoid space in this position. In the prone position satisfactory flow of myodil is obtained, but unless a pad is placed under the patient's chin, the myodil 
will flow into the skull when the patient is placed in the head-down position. The pad causes hyperextension of the neck which is not desirable in a patient with acute injury of the spinal cord. While the myelogram is being performed traction on the skull tongs must be maintained, this is particularly difficult in the head-down position.

A technique suggested by Goodman (1969), utilising a high lateral puncture of the cervical sub-arachnoid space and a circular (Stryker) bed, allows the examination to be performed with less movement of the patient. Since the myodil is introduced in the cervical sub-arachnoid space and then run down towards the feet it is not necessary to put the patient in the head-down position.

\section{Risk of Producing Arachnoiditis}

Introduction of myodil into the sub-arachnoid space may produce an arachnoiditis. Studies on experimental animals have indicated that blood mixed with myodil may potentiate the irritating and inflammatory effect (Howland \& Curry, I966).

Davis and Rumbaugh (1972) feel that the presence of blood in the subarachnoid cerebrospinal fluid is an absolute contra-indication to myelography.

It would be expected in a patient who has sustained trauma to the spinal cord that sub-arachnoid haemorrhage may well have taken place. We have found that those patients with spinal cord trauma associated with fractures of the vertebrae often have blood in the cerebrospinal fluid. Those patients with spinal cord trauma unassociated with fractures of the vertebral column, do not have blood in the cerebrospinal fluid.

\section{Contra-indications to Myelography in Spinal Cord Injury}

\section{Patients with Complete Paralysis of more than 24 Hours' Duration}

Patients with complete motor and sensory paralysis of more than 24 hours' duration will very rarely have any functional recovery, notwithstanding any treatment administered. This observation, which is confirmed by our own experience, is well documented by other workers (Holdsworth, I970; Stauffer, 1975). Norrel (1975) states that myelography is rarely indicated in patients with complete lesions, even those seen within 24 hours of injury.

\section{Anterior Spinal Cord Syndrome}

This syndrome is characterised by immediate complete paralysis, with hypoalgesia to the level of the lesion, and with preservation of motion, position and vibration sense. It is due to trauma to the anterior spinal cord. Schneider (1955), who has done much research on spinal cord injury, feels that myelography is contra-indicated in this syndrome, for fear of causing more damage to the spinal cord.

\section{Central Cord Syndrome}

This syndrome is due to central cord damage and is characterised by disproportionately more motor impairment of the upper than of the lower extremities. Bladder dysfunction and varying degrees of sensory loss below the level of the lesion are also present. 
This syndrome is due to hyperextension injury and therefore hyperextension of the neck, to prevent the flow of myodil into the skull with the patient in the prone position, may aggravate the injury (Schneider et al., 1958).

\section{Indications for Myelography}

Reference to the literature has failed to reveal any simple, clear-cut list of indications for myelography in acute spinal cord injury. We have used the following two indications for myelography.

\section{Progressive Increase in Neurological Deficit after Injury}

This is the single indication where there appears to be a consensus of opinion that myelography should be performed. Care must be taken, however, that true deterioration has taken place. It has been our experience that patients (particularly those referred from other hospitals), who are apparently developing increasing paralysis, have in fact been incorrectly or inadequately assessed on the initial examination.

The history obtained from the patient or his relatives may also be misleading. One patient with a stab wound of the thoracic spine was said to have walked into hospital and subsequently to have developed complete paraplegia. Myelography demonstrated a partial block at the level of the injury. At laminectomy the spinal cord was found to have been completely transected by the knife blade. Clearly the patient could not have walked after the assault and subsequent detailed questioning confirmed this.

In none of the patients, who underwent myelography for progressive increase in the neurological deficit, was any remediable lesion found. The myelographic findings were usually those of incomplete block at the level of injury. In one patient oedema of the cord was demonstrated.

Norrel (1975) reports that three of his patients with increasing paralysis were found at operation to have fragments of intervertebral disc and bone compressing the spinal cord. All three patients improved after operation.

\section{Spinal Cord Injury without Radiological Evidence of Trauma}

In an investigation into patients presenting with post-traumatic tetraplegia without evidence of bony injury on X-ray, myelography was routinely performed as soon after injury as possible (Scher, 1976). The only positive finding was compression of the spinal cord by posterior osteophytic spurs due to cervical spondylosis. No other myelographic abnormality was demonstrated.

In this group of patients, the two conditions most likely to be amenable to treatment are an acute prolapse of an intervertebral disc and an extradural or subdural haematoma. Traumatic posterior herniation of a disc into the spinal canal is rare in the cervical spine, probably because the posterior longitudinal ligament is particularly well-developed and strong in this region. Further posterolaterally the uncus, forming part of the uncovertebral joint, provides a bony barrier against herniation.

In the absence of predisposing conditions, such as bleeding dyscrasias or ankylosing spondylitis, traumatic subdural or extradural haematomas rarely occur in the spinal canal.

Another major indication for myelography used by some centres, is to establish whether there is a block to the flow of myodil. At the time of performing 
the lumbar puncture for myelography, a Quenckenstedt test (bilateral jugular vein compression with observation of spinal fluid manometrics) is performed to determine the patency of the sub-arachnoid space at the level of injury. Some surgeons (particularly in the U.S.A.) base the need for immediate operation, to relieve the pressure on the spinal cord, on the presence of a myelographic and/or manometric block.

Significant extramedullary spinal cord compression may exist in the presence of normal spinal manometrics. On the other hand the block may be due entirely to intramedullary swelling of the spinal cord as shown in Fig. I. There may be complete myelographic obstruction at the level of injury despite normal manometrics. This disparity in findings is due to the fact that while the cerebrospinal fluid will flow around an almost complete obstruction, the viscous myodil will be blocked. Braakman and Penning (I97I) performed serial manometric studies on patients with acute spinal cord injuries. He was unable to establish any clear difference between the recovery of those patients in whom a spinal fluid block existed and those in whom it did not.

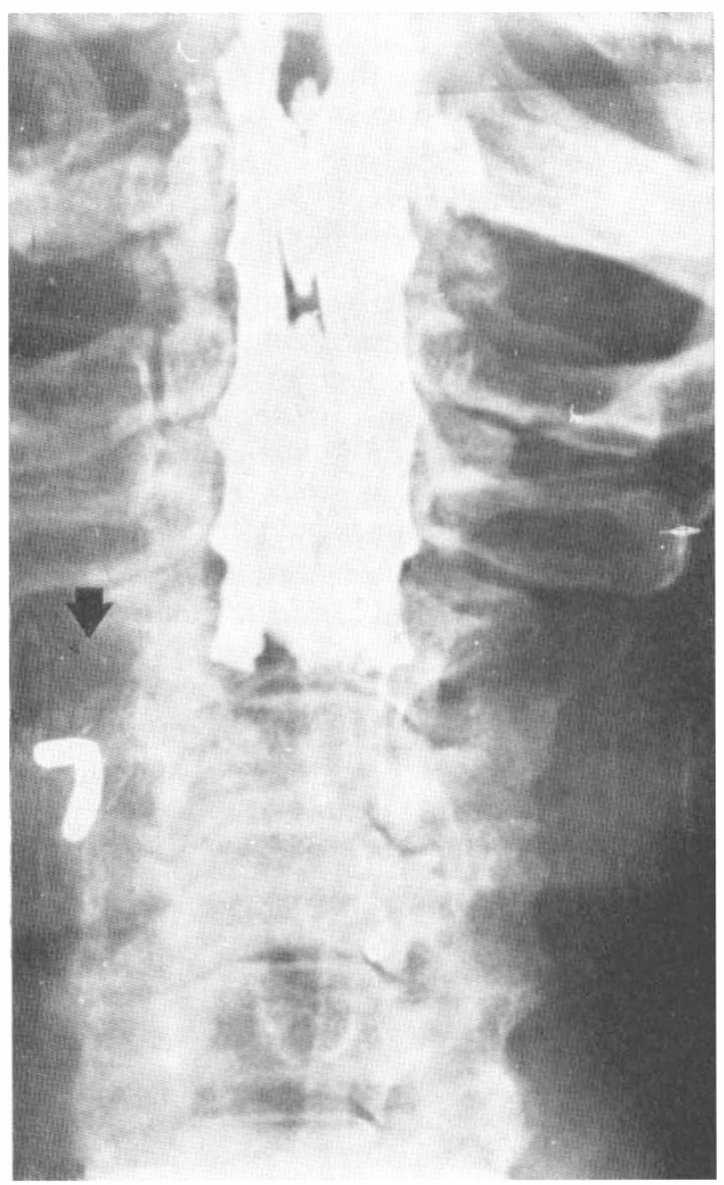

FIG. I

Almost complete obstruction to flow of contrast in lower cervical spinal canal in patient with acute traumatic tetraplegia. At operation only oedema of the spinal cord present. 
For the above reasons we do not feel that myelography for the exclusion of an apparent sub-arachnoid block, is of value.

\section{Difficulty in Interpretation of Myelographic Appearance}

Quite apart from the pros and cons as to whether myelography should be performed in acute spinal cord injury, the interpretation of the myelographic appearance is also a source of difficulty. In most patients the findings are those of a partial or complete block to the flow of contrast medium, apparently extradural in type. It is difficult to differentiate between extradural lesions such as fragments of bone, prolapsed disc or haematoma. In some cases the apparent extradural block is in fact an intramedullary block due to oedema of the spinal cord. Because of the difficulties in interpretation, Braakman and Penning (I97I) feels that there is no value in performing myelography in acute spinal cord injury.

\section{Gas Myelography}

Rossier et al. (1975) have demonstrated the value of gas (negative contrast) myelography in spinal cord injury. This procedure delineates the precise extent of vertebral damage as well as the presence of any posterior disc herniation. It yields a more refined localisation of spinal blocks or cord swelling than the Queckenstedt test and also differentiates a cerebrospinal fluid block due to intrinsic compression, from one caused by extrinsic cord compression. The use of oxygen or air as the contrast medium obviates the necessity for the introduction of myodil into the sub-arachnoid space. Gas myelography, however, requires the use of a Polytome for hypo-cycloidal tomography. This sophisticated unit is not available at our hospital and is not routinely available in smaller X-ray departments. Another disadvantage is that because the examination is time-consuming ( $\mathrm{I} \frac{1}{2}$ hours) and painful, a general anaesthetic is necessary.

\section{Conclusion}

Myelography in patients with acute spinal cord injury is technically a difficult procedure, and is a potentially hazardous examination for the patient. Even when the greatest care is taken it is difficult to avoid some manipulation of the patient's neck. In view of the difficult circumstances under which the examination is carried out removal of the myodil at the completion of the examination may be unsuccessful.

Interpretation of the appearance usually demonstrated is difficult as regards definitive diagnosis. In our experience the examination has not proved to be of value. The only valid indication for positive-contrast myelography appears to be in those patients who show progression of their paralysis after the initial injury. Such patients form a very small percentage of spinal cord injuries.

Negative-contrast myelography appears to be a valuable method of precisely defining the degree of impingement into the spinal canal. Where the necessary facilities are available it will probably be increasingly used in the future.

\section{RÉSUMÉ}

La myelographie par contraste positif pratiquée sur 30 malades présentant des lésions de la moelle épiniére n'a fourni aucune information ayant une valeur clinique. La litterature ne fournit aucune indication de myélographie dans les cas de lésion de la moelle èpiniére. 
On discute les rigues que presente la myélographie chez les malades souffrant de lésion de la moelle èpiniére. On decrit les contre-indications specifiques. On souligne les difficultés rencontrées dans l'interpretation radiologique des images myélographiques dans les lésions de la moelle èpiniére. On en vient á la conclusion que la myélographie par contraste positif dans les lésions de la moelle èpiniére n'a qu'une indication trés limitée.

\section{ZUSAMMENFASSUNG}

Positiv-kontrast 'Myelography' hat in 30 Patienten mit akuter 'cervical' Wirbelsäulenverletzung keine Information von klinischem Wert ergeben. Bestehende Literatur zeigt keine bestimmten Merkmale für 'Myelography' mit akuter Wirbelsäulenverletzung. Es wurde daher ein Versuch gemacht, die Symptome für diesen Zweck zu bewerten. Die potentiellen Probleme von 'Myelography' in Patienten mit akuter Wirbelsäulenverletzung werden besprochen. Spezifische Gegenindikationen sind beschrieben. Schwierigkeiten der Interpretation der radiologischen Darstellung von 'Myelography' bei gewöhnlich vorkommenden Wirbelsäulenverletzungen sind erwähnt. Die Vorteile von negativ-kontrast 'myelography' sind kurz beschrieben. Man kommt zum Schluss, dass die Myelographie einen nur begrenzten Wert hat.

\section{REFERENCES}

Braakman, R. \& Penning, L. (1971). Injuries of the Cervical Spine. Excerpta Medica, Amsterdam, p. II 8.

Davis, O. \& Rumbaugh, C. L. (1972). Pantopaque myelography. In 'Seminars in Roentgenology', 7, 197-I99.

Goodman, J. M. (I969). Myelography in acute cervical injuries. American fournal of Roentgenology, 107, 49I-49I.

HoldswORTH, F. (I970). Fractures, dislocations and fracture-dislocations of the spine. F. Bone and foint Surgery, 52A. I 534-I 55 I.

Howland, W. J., CURRY, I. L. \& BUTLER, A. K. (I963). Pantopaque arachnoiditis. American fournal of Roentgenology, 80, 489-49I.

Norrel, A. H. (1975). Fractures and dislocations of the spine. In The Spine. W. B. Saunders, Philadelphia, p. 53 I.

Rogers, W. A. (1957). Fractures and dislocations of the cervical spine. An end result study. F. Bone and foint Surgery, 53B, 392-405.

Rossier, A. B., Berney, J., Rosenbaum, A. E. \& Hachen, J. (1975). Value of gas myelography in early management of cervical spinal cord injuries. $\mathcal{F}$. Neurosurgery, 42, 330-337.

STAUFFER, E. S. (1975). Diagnosis and prognosis of acute cervical spinal cord injury. In 'Clinical Orthopaedics and Related Research', No. I I2, pp. 9-I5.

ScHER, A. T. (1975). Cervical spinal cord injury without evidence of fracture or dislocation. South African Medical fournal, 50, 962-964.

SCHNEIDER, R. C. (1955). The syndrome of acute anterior spinal cord injury. F. Neurosurgery, 12, 95-122.

Schneider, R. C., THOMPson, M. J. \& Bebin, J. (I958). The syndrome of acute central cervical spinal cord injury. F. Neurology, Neurosurgery and Psychiatry, 21, 216-227. 